\title{
Cytotoxicity and Survival Fitness of Invasive covS Mutant of Group A Streptococcus in Phagocytic Cells
}

\author{
Chuan Chiang-Nii ${ }^{1,2,3 *}$, Yong-An Shi ${ }^{2}$, Chih-Ho Lai ${ }^{1,2,3}$ and Cheng-Hsun Chiu ${ }^{2,3,4}$ \\ ${ }^{1}$ Department of Microbiology and Immunology, College of Medicine, Chang Gung University, Taoyuan, Taiwan, ${ }^{2}$ Graduate \\ Institute of Biomedical Sciences, College of Medicine, Chang Gung University, Taoyuan, Taiwan, ${ }^{3}$ Molecular Infectious \\ Disease Research Center, Chang Gung Memorial Hospital, Taoyuan, Taiwan, ${ }^{4}$ Department of Pediatrics, Chang Gung \\ Children's Hospital, Taoyuan, Taiwan
}

OPEN ACCESS

Edited by:

Mattias Collin,

Lund University, Sweden

Reviewed by:

Michael J. Federle,

University of Illinois at Chicago,

United States

Tecia Maria Ulisses Carvalho,

Universidade Federal do Rio

de Janeiro, Brazil

*Correspondence:

Chuan Chiang-N

entchuan@gap.cgu.edu.tw

Specialty section:

This article was submitted to

Infectious Diseases,

a section of the journal

Frontiers in Microbiology

Received: 10 August 2018

Accepted: 11 October 2018

Published: 30 October 2018

Citation:

Chiang-Ni C, Shi Y-A, Lai C-H and

Chiu C-H (2018) Cytotoxicity

and Survival Fitness of Invasive covS

Mutant of Group A Streptococcus

in Phagocytic Cells.

Front. Microbiol. 9:2592.

doi: 10.3389/fmicb.2018.02592
Group A streptococci (GAS) with spontaneous mutations in the CovR/CovS regulatory system are more invasive and related to severe manifestations. GAS can replicate inside phagocytic cells; therefore, phagocytic cells could serve as the niche to select invasive covS mutants. Nonetheless, the encapsulated covS mutant is resistant to phagocytosis. The fate of intracellular covS mutant in phagocytic cells and whether the intracellular covs mutant contributes to invasive infections are unclear. In this study, capsuledeficient $\left(\mathrm{cap}^{-}\right)$strains were utilized to study how intracellular bacteria interacted with phagocytic cells. Results from the competitive infection model showed that the cap ${ }^{-}$ covS mutant had better survival fitness than the cap- wild-type strain in the PMAactivated U937 cells. In addition, the cap ${ }^{-}$covS mutant caused more cell damages than the cap ${ }^{-}$wild-type strain and encapsulated covS mutant. Furthermore, treatments with infected cells with clindamycin to inhibit the intracellular bacteria growth was more effective to reduce bacterial toxicity than utilized penicillin to kill the extracellular bacteria. These results not only suggest that the covS mutant could be selected from the intracellular niche of phagocytic cells but also indicating that inactivating or killing intracellular GAS may be critical to prevent invasive infection.

Keywords: group A Streptococcus, CovR/CovS, phagocytic cell, clindamycin, intracellular survival

\section{INTRODUCTION}

Streptococcus pyogenes (group A Streptococcus, GAS) is a Gram-positive human pathogen causing diseases including pharyngitis, scarlet fever, impetigo, cellulitis, necrotizing fasciitis, and toxic shock syndrome (Olsen and Musser, 2010). Severe manifestations such as necrotizing fasciitis and toxic shock syndrome are associated with high mortality and substantial economic burden (Olsen and Musser, 2010; Hughes et al., 2015; Stevens and Bryant, 2017). More importantly, an increasing number of scarlet fever and necrotizing fasciitis cases has been reported worldwide in recent decades (Athey et al., 2016; Engelthaler et al., 2016; Lee et al., 2017; Kim and Cheong, 2018).

Acquired prophages have been considered the critical genetic cause of increased GAS virulence and invasiveness (Beres et al., 2002; Aziz et al., 2004; Sumby et al., 2005). In another aspect, the growing evidence provided by next generation sequencing analyses suggests that spontaneous mutations in the regulatory proteins of GAS are highly related to the increase in bacterial invasiveness and severe invasive infections (Friaes et al., 2015b). For example, mutations that result 
in inactivating the CovR/CovS two-component regulatory system cause derepression of virulence factors such as hyaluronic acid capsule, streptolysin O (SLO), and DNase Sda1 (Sumby et al., 2006; Walker et al., 2007). Hyaluronic acid capsule is the key structure for GAS to resist phagocytosis (Stollerman and Dale, 2008). SLO is a pore-forming toxin that has important roles in GAS escaping from phagolysosome and resistance to intracellular killing mechanisms (O'Seaghdha and Wessels, 2013; O'Neill et al., 2016). Furthermore, DNases Sdal degrades the DNA structure of neutrophil extracellular traps (NETs) to help GAS escape from NETs killing (Walker et al., 2007). Phagocytic cells are crucial to the early control of GAS infection (Goldmann et al., 2004). Therefore, $\operatorname{cov} S$ and $\operatorname{cov} R$ mutants are more resistance to phagocytic killing than the wild-type strain. In line with these studies, strains with spontaneous mutations in the $\operatorname{cov} R$ or covS gene were more frequently isolated from patients with severe manifestations compared to patients with mild pharyngeal infections (Ikebe et al., 2010; Friaes et al., 2015b).

Neutrophil extracellular traps have been proposed as the critical pressure to select covs mutants during infection (Walker et al., 2007). Li et al. (2014) have shown that the depletion of neutrophils resulted in reduced frequency of isolated $\operatorname{cov} R$ or $\operatorname{cov} S$ mutants from the mouse infection model. GAS has ability to inhibit azurophilic granule fusion with phagosome and avoid ubiquitylation and recognition by the host autophagy pathway (Staali et al., 2006; Barnett et al., 2013). In line with these observations, several reports showed that GAS survive and even replicate in the intracellular niche of endothelial cells, human monocyte-derived macrophages, and polymorphonuclear leukocytes (Medina et al., 2003a; Staali et al., 2006; Hertzen et al., 2010; Lu et al., 2015; O’Neill et al., 2016). Spontaneous mutations occur while bacteria replicate, and mutant variants are selected by environmental stresses. Therefore, covS mutant might appear in the intracellular niche and be selected by the pressure of intracellular killing mechanisms. Nonetheless, the encapsulated covs mutant is resistant to phagocytosis (Sumby et al., 2006) and the fate of intracellular covS mutant in phagocytic cells is unknown.

The aim of this study was to elucidate whether inactivation of CovS affects the fitness of GAS in phagocytic cells and whether the intracellular covS mutant has roles in the pathogenesis of severe invasive GAS infections. Results from the competitive infection model showed that the covS mutant has better fitness than the wild-type strain in phagocytic cells. Furthermore, the intracellular covS mutant is more toxic to the phagocytic cells than the intracellular wild-type strain and encapsulated extracellular covs mutant. These results suggesting that the inactivation of CovR/CovS regulation plays prominently in interaction with phagocytic cells.

\section{MATERIALS AND METHODS}

\section{Bacterial Strains and Culture Cell Lines}

GAS A20 (emm1 type) and its animal-passage covS mutant AP3 strains were used in the previous study and shown in Table 1 (Chiang-Ni et al., 2016). Briefly, strain AP3 was isolated from the spleen of A20-infected BALB/c mouse (subcutaneous infection) after 3 days of infection. Strain AP3 was genome sequenced. In addition to the frameshift $143 \mathrm{~T}$ deletion in the covS was identified, another five SNPs and an Indel were found in the repeat sequence regions of transposases or rRNA genes (data not shown). To be noted, trans-complementation of $\operatorname{cov} R / \operatorname{cov} S$ in AP3 restored the expression of CovR-controlled genes to the levels similar to its parental A20 strain (Chiang$\mathrm{Ni}$ et al., 2016, 2017). GAS strains were cultured in TSB supplemented with 5\% yeast extract (Becton, Dickinson and Company, Sparks, MD, United States). Escherichia coli $\mathrm{DH} 5 \alpha$ was purchased from Yeastern (Yeastern Biotech Co., Ltd., Taipei, Taiwan) and cultured in Luria-Bertani (LB) broth (Becton) at $37^{\circ} \mathrm{C}$ with vigorous aeration. When appropriate, the antibiotic chloramphenicol (25 and $3 \mu \mathrm{g} / \mathrm{mL}$ for E. coli and GAS, respectively) was used for selection. Human leukemic monocyte lymphoma cell line U937 was cultured in RPMI medium supplemented with $10 \%$ of fetal calf serum (FCS) (Invitrogen, Waltham, MA, United States) at $37^{\circ} \mathrm{C}$ with $5 \% \mathrm{CO}_{2}$.

\section{Construction of hasA, slo, and $\mathrm{SpeB}_{\mathrm{C} 192 \mathrm{~S}}$ Mutants}

The has $A$ gene including its upstream (730 bp) and downstream (572 bp) regions was amplified using primers hasA-F-3 and has A$\mathrm{R}-3$, and ligated into the temperature-sensitive vector $\mathrm{pCN} 143$ (Chiang-Ni et al., 2016) with the BamHI site. The hasA gene was removed using inverted polymerase chain reaction (PCR) with primers del-hasA-F-SacII and del-hasA-R-SacII to generate pCN158. The chloramphenicol cassette of Vector 78 (Chiang$\mathrm{Ni}$ et al., 2017) was amplified using primers Vec78_cat-FSacII and Vec78_cat-R-SacII, and ligated into pCN158 with the SacII site to generate pCN159. To construct the slo mutant, the slo gene including its upstream (872 bp) and downstream (936 bp) regions was amplified using primers Slo-F-3 and SloR-3, and ligated into pCN143 with the BamHI site. The slo gene was removed using inverted PCR with primers del-sloF-sacI and del-slo-R-sacI, and replaced by a chloramphenicol cassette from Vector 78 to generate pCN171. All primers used in this study are described in Table 2. Plasmids pCN158, pCN159, and pCN171 (Table 1) were transformed into GAS strains by electroporation, and transformants were selected using spectinomycin at $30^{\circ} \mathrm{C}$. Transformants were incubated at $37^{\circ} \mathrm{C}$ with the spectinomycin selection to force plasmid integration via single homologous recombination. Finally, transformants were transferred in antibiotic-free plate at $30^{\circ} \mathrm{C}$ to force plasmid excision from the chromosome via a second recombination. Transformants with double homologous recombination were selected by changes in colony morphology or chloramphenicol resistance. The deletion of target gene in the transformants was confirmed by sequencing.

To construct $\mathrm{SpeB}_{\mathrm{C} 192 \mathrm{~S}}$ mutation strain, the speB gene (640 bp) with the mutation in T574 was amplified using primers $S_{\text {peB }} B_{C 2 S}-F-1$ and $S_{\text {peB }} B_{C 192 S}-\mathrm{R}-1$ (Table 2) from pET21a::speB $B_{\mathrm{T} 574 \mathrm{~A}}$ (Chen et al., 2003), and ligated into pCN143 with the HindIII site to construct pCN144 (Table 1). The plasmid pCN144 was transformed into SCN162 (hasA mutant 
TABLE 1 | Plasmids and bacterial strains used in this study.

\begin{tabular}{|c|c|c|c|}
\hline Plasmid/Strain & Parental strain & Description & Reference \\
\hline Vector 78 & - & $\begin{array}{l}\text { Chloramphenicol } \\
\text { cassette }\end{array}$ & $\begin{array}{l}\text { Chiang-Ni } \\
\text { et al., } 2016\end{array}$ \\
\hline pCN143 & - & $\begin{array}{l}\text { Temperature-sensitive } \\
\text { vector }\end{array}$ & $\begin{array}{l}\text { Chiang-Ni } \\
\text { et al., } 2016\end{array}$ \\
\hline pCN144 & - & pCN143::SpeB ${ }_{C 192 S}$ & This study \\
\hline pCN158 & - & $\begin{array}{l}\text { pCN143 carried the } \\
\text { marker-less hasA } \\
\text { deletion DNA fragment }\end{array}$ & This study \\
\hline pCN159 & - & pCN143::hasA $\Delta \mathrm{cm}$ & This study \\
\hline pCN171 & - & pCN143::slo $\Delta \mathrm{cm}$ & This study \\
\hline A20 & - & $\begin{array}{l}\text { emm1-type wild-type } \\
\text { strain }\end{array}$ & $\begin{array}{l}\text { Chiang-Ni } \\
\text { et al., } 2009\end{array}$ \\
\hline AP3 & A20 & $\begin{array}{l}\text { Animal-passaged } \\
\text { strain, covS mutant }\end{array}$ & $\begin{array}{l}\text { Chiang-Ni } \\
\text { et al., } 2016\end{array}$ \\
\hline SCN156 & A20 & hasA mutant $\left(\mathrm{Cm}^{\mathrm{S}}\right)$ & This study \\
\hline SCN157 & AP3 & hasA mutant $\left(\mathrm{Cm}^{\mathrm{S}}\right)$ & This study \\
\hline SCN158 & AP3 & has $A$ mutant $\left(\mathrm{Cm}^{\mathrm{R}}\right)$ & This study \\
\hline SCN162 & A20 & has $A$ mutant $\left(\mathrm{Cm}^{\mathrm{R}}\right)$ & This study \\
\hline SCN176 & SCN157 & slo mutant & This study \\
\hline SCN208 & SCN162 & SpeB $_{\mathrm{C} 192 \mathrm{~S}}$ mutant & This study \\
\hline
\end{tabular}

of A20), and transformants were selected by spectinomycin $(100 \mu \mathrm{g} / \mathrm{mL})$ at $30^{\circ} \mathrm{C}$. Transformants were incubated at $37^{\circ} \mathrm{C}$ to force plasmid integration via single homologous recombination. Finally, transformants in which the plasmid was excised from the chromosome via a second recombination were selected in antibiotic-free plate at $30^{\circ} \mathrm{C}$. The proteasenegative transformants were screened on skim-milk agar plate (Chiang-Ni et al., 2016). The $\mathrm{SpeB}_{\mathrm{C} 192 \mathrm{~S}}$ mutation in the selected transformants was further verified by sequencing, and the strain was designated as SCN208 (Table 1).

\section{U937 Cells Infection Model}

The U937 cell line is a suspension, oncogenic human monocyte cell line and has the potential of differentiating into either macrophages or dendritic cells (Lawrence and Natoli, 2011).

TABLE 2 | Primers used in this study.

\begin{tabular}{ll}
\hline Primer & Sequence $\mathbf{( 5}^{\prime} \mathbf{-} \mathbf{3}^{\prime} \mathbf{)} \#$ \\
\hline hasA-F-3 & cgggatccttccccattgcaagcatatc \\
hasA-R-3 & cgggatcctgcaaattttctgcgtctg \\
del-hasA-F-sacll & tccccgcggtaatatgtgcatcgagtagt \\
del-hasA-R-sacll & tccccgcggcacaattacacctctttctt \\
vec78_cat-F-sacll & tccccgcgggatagatttatgatatag \\
vec78_cat-R-sacll & tccccgcggatttattcagcaagtctt \\
Slo-F-3 & gcgggatccgcggaaaatatagcgatgga \\
Slo-R-3 & gcgggatcctgttaagaggttggggcaag \\
del-slo-F-sacl & tccgagctcggtttgaaccgcttggtaaa \\
del-slo-R-sacl & tccgagctctggagaagaagcagggaaaa \\
SpeBc192S-F-1 & cgaagcttatgctggtaccgctgagatt \\
SpeB & cgaagcttttacgtccgtcagcaccatc \\
\hline
\end{tabular}

\#Underline, restriction enzyme site.
PMA (phorbol 12-myristate 13-acetate) is a phorbol ester capable of transforming monocytic cells toward the macrophage pathway. After PMA treatments, U937 cells form tight clusters and attach to the plastic surface (Garcia et al., 1999). In the present study, U937 cells were treated FCS-containing RPMI medium with $15 \mathrm{nM}$ of PMA (1.5 mM in DMSO; SI-D2650, Sigma-Aldrich, St. Louis, MO, United States) for 3 days to induce cell differentiation from monocyte-like to macrophage-like cells. Differentiated U937 macrophages were cultured in 6-well plates at a density of $1 \times 10^{6} \mathrm{cell} / \mathrm{mL}$. In experiments that were needed to inhibit phagocytosis, U937 macrophages were treated with $10 \mu \mathrm{g} / \mathrm{mL}$ cytochalasin D (10 mg/mL in DMSO; C8273, SigmaAldrich) for $1 \mathrm{~h}$ before infection, and the same concentration of cytochalasin D was present in the medium during the infection. The overnight bacterial cultures were transferred to fresh broth at 1:50 dilution to an optical density at $600 \mathrm{~nm}$ of $0.5-0.6$. Bacteria were washed and resuspended in FCS-free RPMI medium and opsonized with human IgG (1 mg/mL; I8640, Sigma-Aldrich) at $37^{\circ} \mathrm{C}$ for $30 \mathrm{~min}$ before infection. PMA-activated U937 cells were infected with the opsonized GAS at multiplicity of infection (MOI) of 0.5 , 5, or 50 in FCS-free RPMI medium with centrifugation at $335 \times g$ for 3 min to facilitate and synchronize the infection. After $30 \mathrm{~min}$ of infection, the infected U937 cells were washed and treated with gentamicin $(100 \mu \mathrm{g} / \mathrm{mL})$, penicillin $(10 \mu \mathrm{g} / \mathrm{mL})$, clindamycin $(10 \mu \mathrm{g} / \mathrm{mL})$, or penicillin plus clindamycin, depending on different experimental conditions. After infection, cells were washed with $1 \times$ phosphate-buffered saline (PBS) twice and lysed with $0.01 \%$ Triton X-100 for $5 \mathrm{~min}$. The cell lysates were serial diluted and plating on TSBY plate for determining the number of survival GAS.

\section{LDH Cytotoxicity Assay}

Culture supernatants of infected cells were collected by centrifugation at $250 \times g$ for $5 \mathrm{~min}$. The release of lactate dehydrogenase (LDH) was measured by CytoTox96 ${ }^{\circledR}$ NonRadioactive Cytotoxicity Assay (Promega, Fitchburg, WI, United States), according to the manual. The cytotoxicity (\%) was calculated as follows: [(sample LDH release-medium blank)/(maximum LDH release-medium blank)] $\times 100$. The maximum $\mathrm{LDH}$ release was indicated as the $\mathrm{LDH}$ released from uninfected cells treated with lysis buffer for $45 \mathrm{~min}$ at $37^{\circ} \mathrm{C}$.

\section{Hyaluronic Acid Capsule ELISA Assay}

The hyaluronic acid capsule extraction was performed according to the method described previously (Henningham et al., 2014). Briefly, overnight culture bacteria were collected and washed with PBS. $400 \mu \mathrm{L}$ of bacterial suspension was mixed with $1 \mathrm{~mL}$ of chloroform and shaken for $3 \mathrm{~min}$ in the Mini-BeadBeater (BioSpec Products Inc., Bartlesville, OK, United States). Supernatants were collected by centrifugation at $13,200 \times g$ for $20 \mathrm{~min}$ at $4^{\circ} \mathrm{C}$ and analyzed with the Hyaluronan DuoSet ELISA kit (DY3614-05, R\&D Systems, Minneapolis, MN, United States) according to the manual.

\section{Western Blot}

The bacterial culture was collected by centrifugation at 2,850 $\times g$ for $10 \mathrm{~min}$ at $4^{\circ} \mathrm{C}$ and sterilized using a $0.22 \mu \mathrm{m}$ filter. Bacterial 
culture supernatants $(30 \mu \mathrm{L})$ were mixed with $6 \times$ protein loading dye and separated by $12 \%$ sodium dodecyl sulphatepolyacrylamide gel electrophoresis (SDS-PAGE). Proteins were transferred onto polyvinylidene difluoride (PVDF) membranes and the membranes were incubated with 5\% skim milk in PBST buffer $(1 \times$ PBS containing $0.2 \%$ of Tween-20) at room temperature $\left(25-30^{\circ} \mathrm{C}\right)$ for $1 \mathrm{~h}$. SpeB and SLO were detected by anti-SpeB (Toxin Technology, Inc., Sarasota, FL, United States) and anti-SLO (Abcam, Cambridge, United Kingdom) antibodies, respectively. The blot was developed using Pierce ECL Western Blotting Substrate (Thermo Fisher Scientific Inc., Rockford, IL, United States), and the signal was detected using the Gel Doc $\mathrm{XR}+$ system (BioRad, Hercules, CA, United States).

\section{Statistics Analysis}

Statistical analysis was performed by using Prism software, version 5 (GraphPad, San Diego, CA, United States). Significant differences in multiple groups were determined using ANOVA. Post-test for ANOVA was analyzed by Tukey's Honestly Significant Difference test. A $p$-value $<0.05$ was considered statistically significant.

\section{RESULTS}

\section{Inactivation of the Hyaluronic Acid Capsule Synthesis in the Animal-Passage covS Mutant Increases Its Interaction and Cytotoxicity With Phagocytic Cells at High MOI Conditions}

The increased production of hyaluronic acid capsule in the covs mutant contributes to enhancing bacterial resistance to phagocytosis (Sumby et al., 2006). In order to evaluate how the animal-passage covS mutant (AP3) interacts with phagocytic cells, hasA mutants of wild-type A20 strain and AP3 were constructed. The concentration of hyaluronic acid capsule in the extract from A20 and AP3 was $0.96 \pm 0.14$ and $215.29 \pm 57.36 \mathrm{ng} / \mathrm{mL}$, respectively. In addition, the hyaluronic acid capsule was not detected (under the detection limits) in extracts from A20 and AP3 hasA mutants. PMAactivated U937 cells were infected with the IgG-opsonized $\mathrm{A} 20, \mathrm{AP} 3$, and their has $A$ mutants at $\mathrm{MOI}$ of 50 at $37^{\circ} \mathrm{C}$ for $30 \mathrm{~min}$, and the number of cell-associated bacteria was analyzed using plating method. As expected, the number of cell-associated hasA mutant of AP3 (SCN157) was increased significantly compared to that of AP3 (Figure 1A), indicating that inactivation of hyaluronic acid capsule production increases bacteria binding to or being phagocytosed by phagocytic cells. Nonetheless, although the number of cell-associated SCN157 and SCN156 (hasA mutant of A20) was comparable, fewer viable intracellular SCN157 could be recovered after another $45 \mathrm{~min}$ of incubation (Figure 1B). In addition, we found that SCN157 caused more cell damage compared to other strains under microscope observations (Supplementary Figure 1), suggesting that SCN157 is toxic to PMA-activated U937 cells and therefore fewer intracellular SCN157 could be recovered after infection. The cytotoxicity of A20, AP3, SCN156, and SCN157 on PMA-activated U937 cells was further evaluated using the LDH assay. PMA-activated U937 cells were infected with these strains at $\mathrm{MOI}=50$ for $45 \mathrm{~min}$, and supernatants were collected for this assay. Results showed that the cell damage in SCN157-infected cells was 2.46- and 1.8-fold higher as compared to that in cells infected with its parental AP3 strain and SCN156, respectively (Figure 1C). To evaluate whether the decrease in the number of intracellular SCN157 was related to its cytotoxicity, the cell-association and intracellular survival amount and cytotoxicity of these GAS strains under low MOI conditions $(\mathrm{MOI}=0.5)$ were further evaluated. Results showed that SCN156 and SCN157 had similar cytotoxicity, cellassociation, and intracellular survival amounts in PMA-activated U937 cells (Figures 1D-F). These results indicate that deletion of has $A$ increases the interaction between bacteria and phagocytic cells. In addition, the decrease in the number of intracellular SCN157 at MOI = 50 can be related to its increased cytotoxicity (Figures 1B,C).

\section{The Survival Fitness of Capsule-Deficient A20 and AP3 Strains in Culture Broth and PMA-Activated U937 Cells}

Gentamicin cannot penetrate through the mammalian cell membrane (Elsinghorst, 1994; Barnett et al., 2013). If the cell membrane is damaged, intracellular bacteria could be exposed to gentamicin and complicates the ability to evaluate bacterial survival fitness in phagocytic cells. We found that the fewer intracellular viable SCN157 was observed under high MOI $(\mathrm{MOI}=50)$ but not low MOI (MOI $=0.5)$ conditions, suggesting that the increase in cytotoxicity of SCN157 could be related to the increase in susceptibility of intracellular SCN157 to gentamicin treatment (Supplementary Figure 2). In addition, this property may provide SCN157 with better resistance to phagocytic killing. SCN156 and SCN157 are markerless has $A$ mutants. In order to compare the survival fitness of the capsule-deficient wild-type and $\operatorname{cov} S$ mutant strains by competitive infection model, a chloramphenicol-resistant $\left(\mathrm{Cm}^{\mathrm{R}}\right)$ hasA mutant of A20 (SCN162) and AP3 (SCN158) was constructed. The growth activity of selected strains in culture broth was first compared. An equal number of SCN162 $\left(\mathrm{Cm}^{\mathrm{R}}\right)$ and SCN157 [Cm-susceptible $\left.\left(\mathrm{Cm}^{\mathrm{S}}\right)\right]$ or SCN156 $\left(\mathrm{Cm}^{\mathrm{S}}\right)$ and $\mathrm{SCN} 158\left(\mathrm{Cm}^{\mathrm{R}}\right)$ was mixed and inoculated in trypticase soy broth with yeast extract (TSBY). After incubation, the number of capsule-deficient A20 and AP3 was determined by plating bacteria on TSBY plates with or without Cm selection. Results showed that the growth activity of SCN162 and SCN157 was similar under broth culture conditions (Figure 2A). Nonetheless, SCN158 showed a decrease in the growth activity compared to SCN156 after 2.25-4.25 h of incubation (Figure 2A).

Based on these results, SCN162 and SCN157 were utilized for the following analyses. PMA-activated U937 cells were infected with mixed SCN162 and SCN157 (IgG-opsonized) at MOI $=50$ for $30 \mathrm{~min}$, and the number of survived bacteria was evaluated. At MOI $=50$, we found that the survival 
A

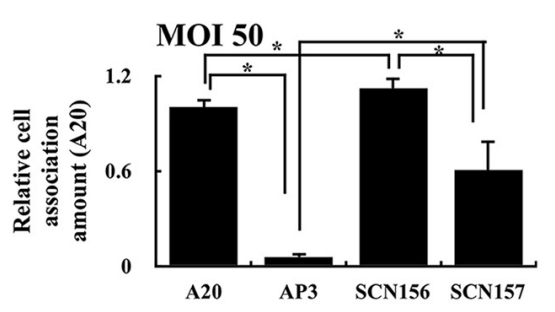

B

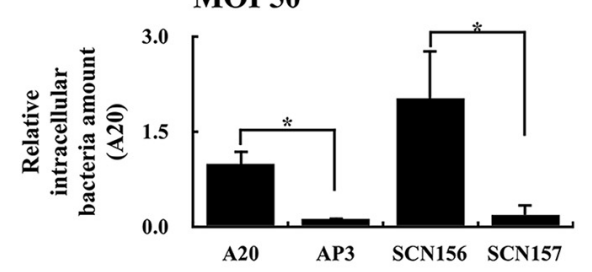

C

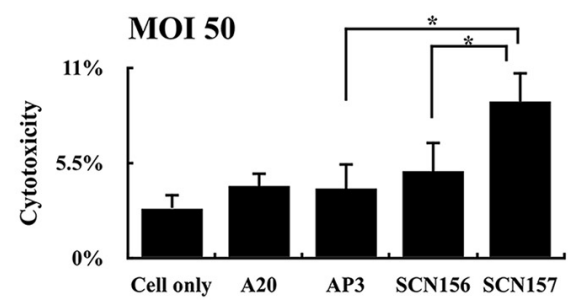

D

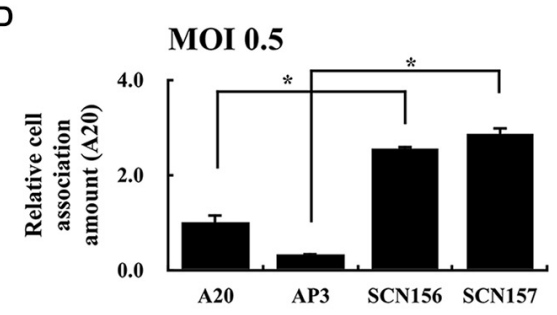

$\mathrm{E}$

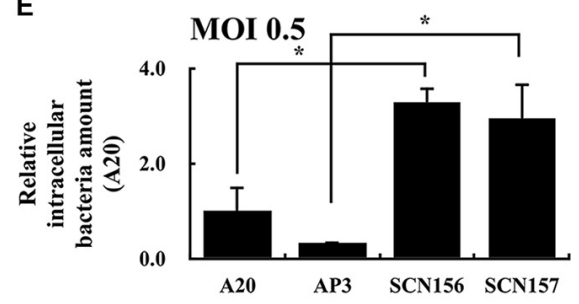

$\mathbf{F}$

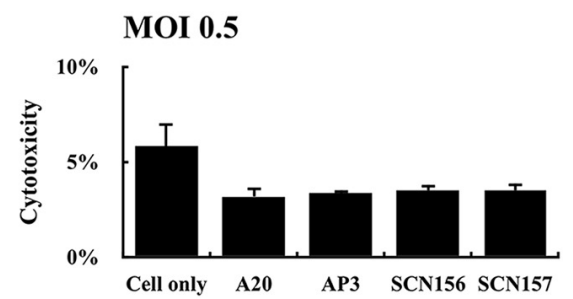

FIGURE 1 | Cell-association and intracellular survival amount of wild-type A20 strain, animal-passage covS mutant AP3, and their capsule-deficient mutants (SCN156 and SCN157, respectively) in PMA-activated U937 cells. (A,D) Cell-association amount of A20, AP3, SCN156, and SCN157 with U937 cells.

PMA-activated U937 cells were infected with the IgG-opsonized GAS strains at multiplicity of infection (MOI) of 50 or 0.5 for 30 min. The infected cells were washed after infection, and the number of cell-associated bacteria was determined using plating method. (B,E) Intracellular survival amount of A20, AP3, SCN156, and SCN157 with U937 cells. PMA-activated U937 cells were infected with the lgG-opsonized GAS strains at MOI of 50 or 0.5 for 30 min. The infected cells were washed after infection and incubated in gentamicin-containing medium for $45 \mathrm{~min}$. After gentamicin treatment, the infected cells were washed, and the number of intracellular bacteria was determined using plating method. (C,F) Cytotoxicity of A20, AP3, SCN156, and SCN157 to U937 cells. PMA-activated U937 cells were infected with the lgG-opsonized bacteria at $\mathrm{MOI}$ of 50 or 0.5 for $45 \mathrm{~min}$, and culture supernatants were collected for evaluating the cytotoxicity by lactic dehydrogenase $(\mathrm{LDH})$ assay. Error bars represent the standard deviations. ${ }^{*} p<0.05$.

rate of SCN157, but not SCN162, was increased after $3.75 \mathrm{~h}$ of incubation (Figure 2B). Furthermore, the changes in the proportion of SCN162 and SCN157 in the recovered bacterial population were analyzed after $0.75-3.75 \mathrm{~h}$ of incubation. After 0.75 and $1.75 \mathrm{~h}$ of incubation, a similar proportion of SCN162 and SCN157 was found in the recovered bacterial population (Figure 2C). Nonetheless, after $3.75 \mathrm{~h}$ of incubation, the proportion of SCN157 increased to $75 \%$ in the recovered bacterial population (Figure $2 \mathrm{C}$ ). Under $\mathrm{MOI}=0.5$ conditions, both SCN156 and SCN157 does not cause damages to PMAactivated cells (Supplementary Figure 2). With the infection protocol described in Figure 2D, SCN162 and SCN157 caused the additional $1.6 \% \pm 0.45$ and $0.95 \% \pm 0.17 \%$ of cell damages compared to the uninfected group after $3.75 \mathrm{~h}$ of incubation at the $\mathrm{MOI}=5$ conditions, respectively. Therefore, $\mathrm{MOI}=5$ was selected as the low MOI conditions for this competitive infection model. At MOI = 5, the survival rate of SCN162 and SCN157 was similar after $0.75-3.75 \mathrm{~h}$ of incubation (Figure 2D); while, the proportion of SCN157 in the recovered bacteria population increased from 49.12 to $61.67 \%$ after $0.75-3.75 \mathrm{~h}$ of incubation (Figure 2E). These results suggest that SCN157 has a better survival fitness than that of SCN162 in PMA-activated U937 cells.

\section{Effects of Cytochalasin D Treatment and Inactivation of SpeB and SLO on Cytotoxicity in PMA-Activated U937 Cells}

Strain SCN157 is more cytotoxic to PMA-activated U937 cells compared to SCN156 after $1.75 \mathrm{~h}$ of infection at the MOI $=50$ conditions (Supplementary Figure 2); however, increase in cell damage was not observed in cells infected with AP3 strain for 45 min (compared to A20; Figure 1C) and SCN157 for $30 \mathrm{~min}$ (compared to SCN162; Figure 3A). However, after additional $45 \mathrm{~min}$ of gentamicin treatment, an increased damage in cells infected with SCN157 and mixed SCN162 and SCN157 was observed (Figure 3B). These results suggest that intracellular SCN157 is more cytotoxic than intracellular SCN162 and extracellular bacteria. Therefore, cytochalasin D was utilized to inhibit phagocytosis, and the cytotoxicity of extracellular and intracellular bacteria in PMA-activated U937 cells was compared. Results showed that cytochalasin D treatment did 


\section{A

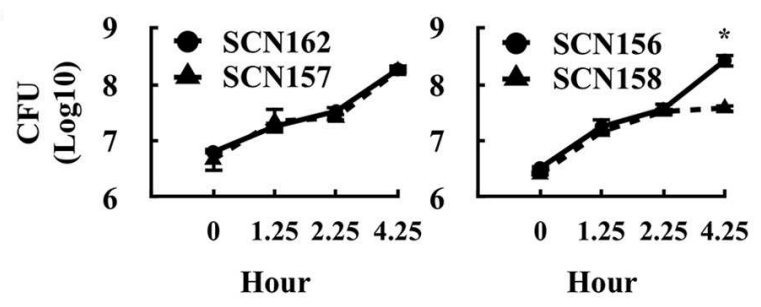

B
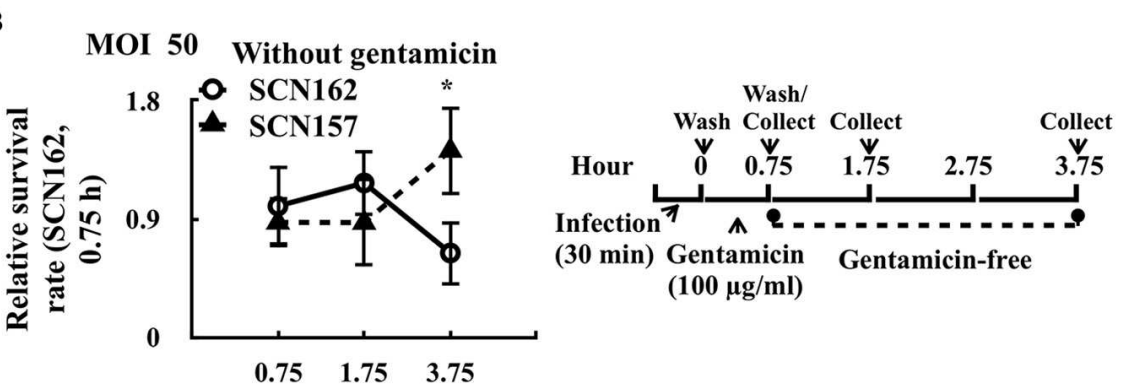

D

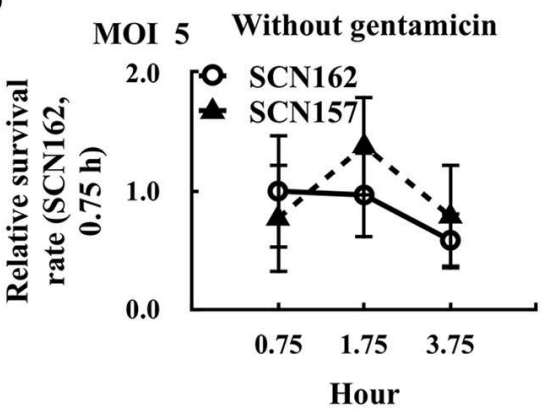

C

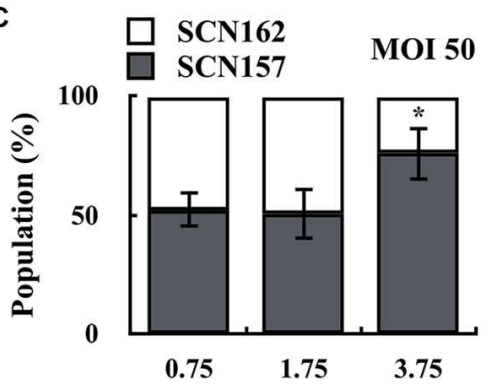

E

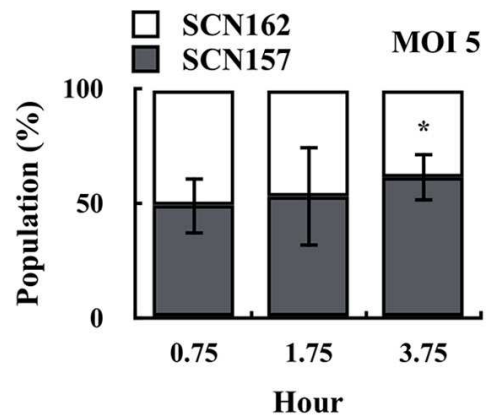

FIGURE 2 | Survival fitness of the capsule-deficient A20 and AP3 in the culture broth and PMA-activated U937 cells. (A) Survival fitness of the capsule-deficient A20 $\left(\mathrm{SCN} 156\left[\mathrm{Cm}^{\mathrm{S}}\right]\right.$ and SCN162 $\left.\left[\mathrm{Cm}^{\mathrm{R}}\right]\right)$ and AP3 $\left(\mathrm{SCN} 157\left[\mathrm{Cm}^{\mathrm{S}}\right]\right.$ and SCN158 $\left.\left[\mathrm{Cm}^{\mathrm{R}}\right]\right)$ in trypticase soy broth with yeast extract (TSBY). An equal number of A20- and AP3-derivative strains was mixed and inoculated in TSBY. After 1.25-4.25 h of incubation, the number of A20 and AP3 mutants was determined using plating method. (B,D) Survival fitness of the capsule-deficient A20 (SCN162 [Cm $\left.{ }^{\mathrm{R}}\right]$ ) and AP3 (SCN157 [Cm $]$ ) in PMA-activated U937 cells at multiplicity of infection (MOI) of 50 and 5 conditions. PMA-activated U937 cells were infected with mixed SCN162 and SCN157. The infection protocol is shown in the right panel. (C,E) The proportion of SCN157 and SCN162 in the recovered bacterial population after cells were infected with mixed SCN162 and SCN157 at MOI of 50 and 5 conditions. $\mathrm{Cm}$ : chloramphenicol. Error bars represent the standard deviations. ${ }^{*} p<0.05$

not influence the cytotoxicity of SCN162 on PMA-activated U937 cells (Figure 3C). Nonetheless, cytochalasin D-treated cells showed 1.94- and 1.7-fold decrease in cell damage compared to untreated cells after SCN157 or mixed SCN162 and SCN157 infection, respectively (Figure 3C). These results not only support that extracellular covS mutant is cytotoxic (Hancz et al., 2017), but also suggest that intracellular covS mutant contributes significantly to causing cell damages.

Mutation in the covS gene leads to the repression of SpeB but upregulation of SLO expression (Sumby et al., 2006). Both SpeB and SLO are involved in bacterial resistance to intracellular killing (Barnett et al., 2013; O'Seaghdha and Wessels, 2013; Lu et al., 2015; O'Neill et al., 2016). Therefore, the effects of the repression of SpeB in SCN162 and upregulation of SLO in SCN157 on contributing to bacterial cytotoxicity in PMAactivated U937 cells was further elucidated. PMA-activated U937 cells were similarly infected with the slo mutant of SCN157 (SCN176) and SpeB protease-inactivated mutant of SCN162 (SpeB $\left.\mathrm{C}_{\mathrm{C} 192 \mathrm{~S}}, \mathrm{SCN} 208\right)$, and the cytotoxicity of these bacterial strains on U937 cells was evaluated. To be noted, the inactivation of SLO expression and SpeB protease activity in SCN176 and SCN208 were confirmed by western blotting (Supplementary Figure 3). Results showed that the cytotoxicity of SCN176 to PMA-activated U937 cells was decreased by 5.52 -fold compared to that of its parental SCN157 strain (Figure 3D). In addition, the 3.81-fold decrease in cell damage was observed in cells infected with mixed SCN162 and SCN176 compared to cells infected with mixed SCN162 and SCN157 (Figure 3D). However, there was no significant difference in the cytotoxicity of SCN208 and its parental SCN162 strain (Figure 3E). Furthermore, the damage of cells infected with mixed SCN157 and SCN162 and mixed SCN157 and SCN208 was similar (Figure 3E). These 


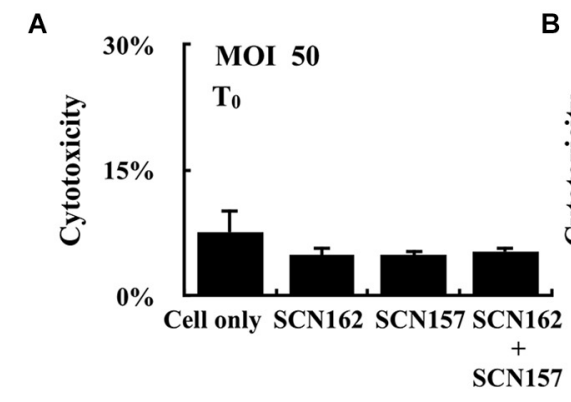

C

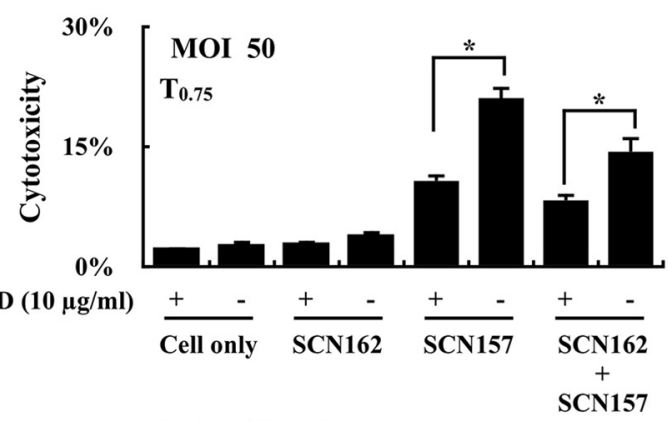

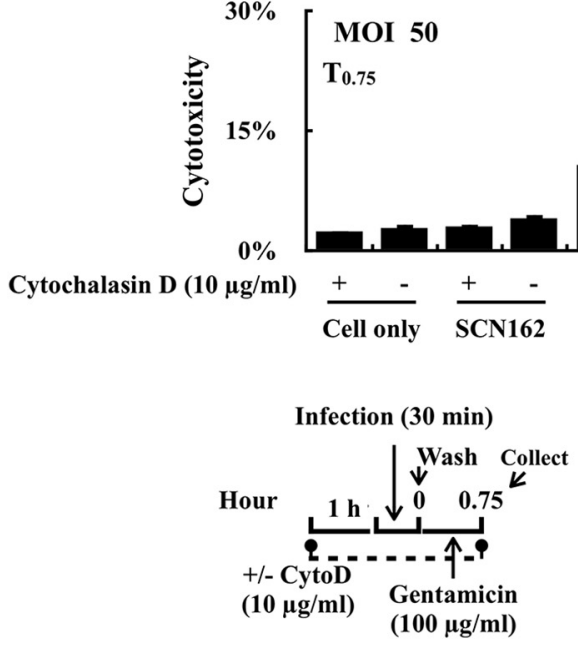

B $30 \%$

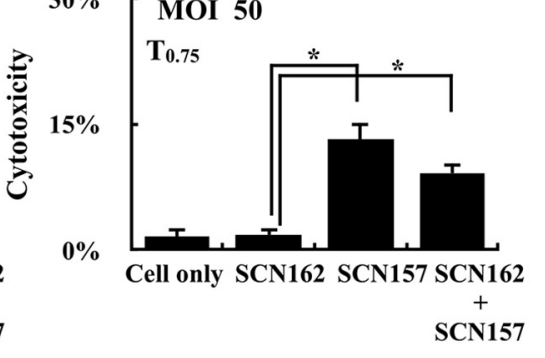

Infection (30 min) Collect

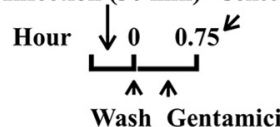

Wash Gentamicin or
Collect $(100 \mu \mathrm{g} / \mathrm{ml})$
D

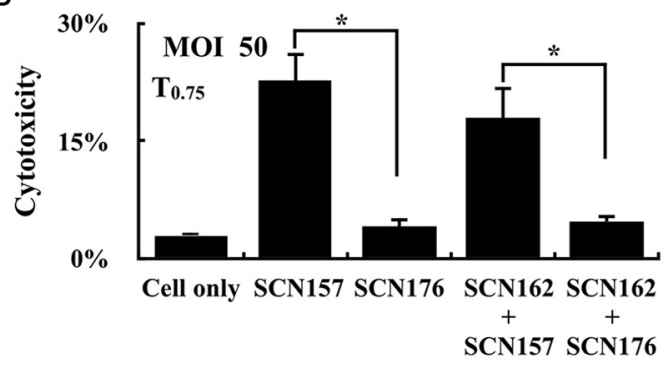

E

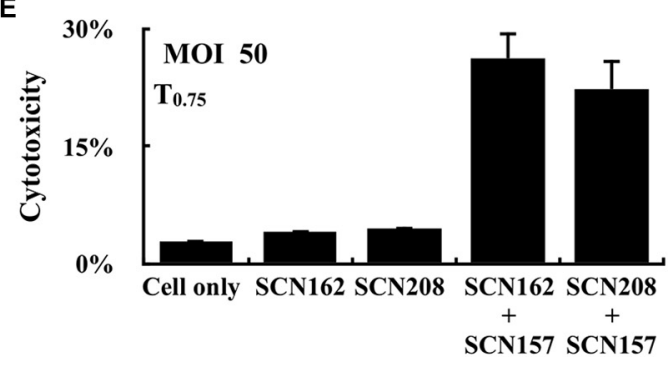

FIGURE 3 | Cytotoxicity of the capsule-deficient A20 and AP3 (SCN162 and SCN157, respectively), SpeB 1 192s mutant of SCN162 (SCN208), and slo mutant of SCN157 (SCN176) on PMA-activated U937 cells with or without cytochalasin D during infection. (A,B) Cytotoxicity of SCN162 and SCN157 on PMA-activated U937 cells after $0.5 \mathrm{~h}\left(\mathrm{~T}_{0}\right)$ and $0.75 \mathrm{~h}\left(\mathrm{~T}_{0.75}\right)$ of infection. The right panel shows the infection protocol of (A,B,D,E). (C) Cytotoxicity of SCN162 and SCN157 on PMA-activated U937 cells with or without cytochalasin D (CytoD) treatment. The lower panel shows the infection protocol. (D,E) Cytotoxicity of SCN162, SCN157, SCN176, and SCN208 on PMA-activated U937 cells. Error bars represent the standard deviations. ${ }^{*} p<0.05$.

results suggest that SLO but not SpeB is critical for the bacterial cytotoxicity on PMA-activated U937 cells.

\section{SLO Contributes to the Increase of Intracellular Survival of the Capsule-Deficient AP3 Strain}

Results shown in Figure 2 indicated that the capsule-deficient AP3 (SCN157) had better fitness in phagocytic cells than the capsule-deficient A20 strain. Furthermore, the slo mutant of SCN157 showed a significant decrease in cytotoxicity compared to its parental strain (Figure 3D). These results suggest that SLO is a critical factor for the increase in survival fitness of SCN157 in this competitive infection model. Therefore, the number of survived SCN156 and slo mutant of SCN157 (SCN176) with PMA-activated U937 cells was further elucidated (Figure 4A). Results showed that the survival rate of SCN156 and SCN176 was similar after $0.75-3.75 \mathrm{~h}$ of infection at both $\mathrm{MOI}=50$ and $\mathrm{MOI}=5$ (Figures 4B,D). In addition, at MOI $=50$, the proportion of SCN176 in the recovered bacterial population decreased gradually from 48.2 to $36.3 \%$ after $0.75-3.75 \mathrm{~h}$ of infection (Figure 4C). At MOI $=5$, the survival rate of SCN156 and SCN176 decreased after $3.75 \mathrm{~h}$ of infection, and the proportion of these strains in the bacterial population was similar after $0.75-3.75 \mathrm{~h}$ of infection (Figures 4D,E). These results indicated that inactivation of SLO expression in covS mutant decreased its activity to compete with SCN156 in PMA-activated U937 cells.

\section{Clindamycin but Not Penicillin Treatment Effectively Inhibits the Cytotoxicity of the Intracellular Capsule-Deficient AP3}

\section{Strain}

GAS is susceptible to penicillin; however, clindamycin is strongly recommended for treating patients with severe manifestations such as necrotizing fasciitis (Stevens et al., 2014). Unlike penicillin that is unable to penetrate through the mammalian cell membrane efficiently (Renard et al., 1987), clindamycin can 
A

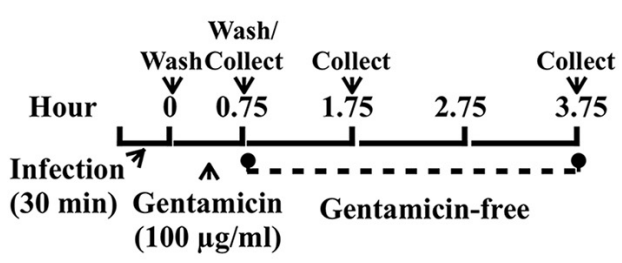

MOI 50

Without gentamicin

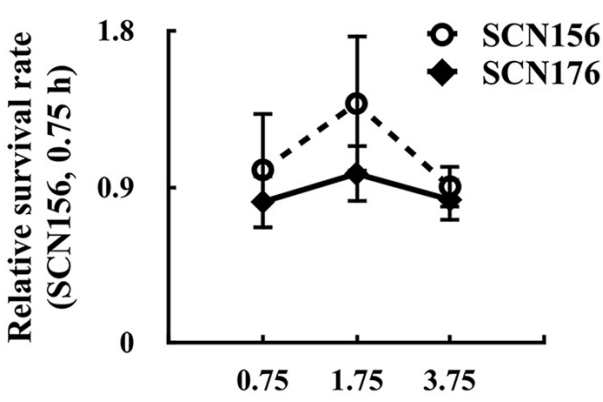

D

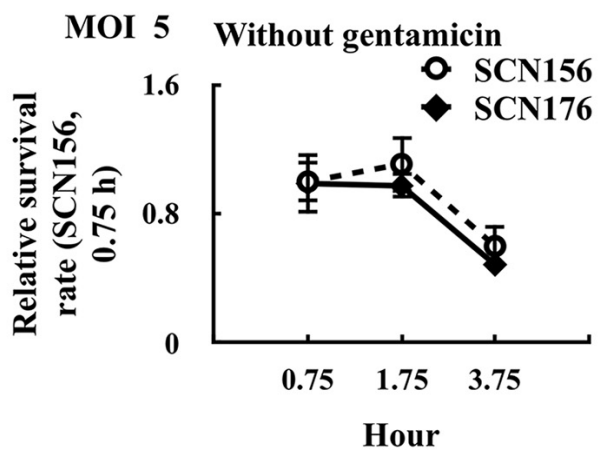

C

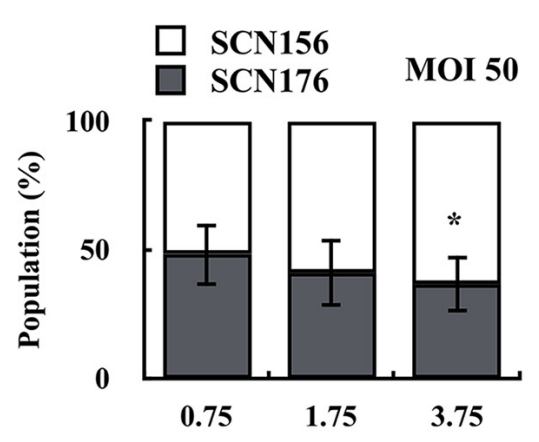

E

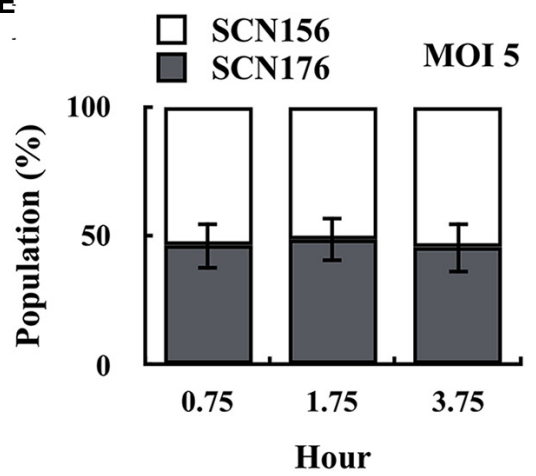

FIGURE 4 | Survival fitness of the capsule-deficient A20 (SCN156), AP3 (SCN157), and slo mutants of SCN157 (SCN176) on PMA-activated U937 cells. PMA-activated U937 cells were infected with mixed (1:1 ratio) SCN156 and SCN176 at multiplicity of infection (MOI) of 50 or 5 as shown in panel (A). (B,D) Survival fitness of SCN156 $\left(\mathrm{Cm}^{\mathrm{R}}\right)$ and SCN176 $\left(\mathrm{Cm}^{\mathrm{S}}\right)$ at MOI of 50 or 5 in gentamicin-free incubation conditions. (C,E) The proportion of SCN156 and SCN176 in the recovered bacterial population at $\mathrm{MOI}$ of 50 or 5 in gentamicin-free incubation conditions. Error bars represent the standard deviations. ${ }^{*} p<0.05$.

reach high intracellular levels in phagocytic cells. Results shown in Figure 3C suggest that intracellular, but not extracellular capsule-deficient covS mutant is critical for causing cell damages. We proposed that clindamycin could be more effective in inhibiting bacterial cytotoxicity than penicillin. To prove this, PMA-activated U937 cells were infected with SCN162 and SCN157 at MOI $=50$, and the infected cells were treated with penicillin or clindamycin. However, penicillin $(10 \mu \mathrm{g} / \mathrm{mL})$ and clindamycin $(10-100 \mu \mathrm{g} / \mathrm{mL})$ treatments did not reduce the cell damage in SCN162- and SCN157-infected cells (data not shown). This high MOI conditions could result in the extensive cell damage that cannot be rescued by the antibiotic treatments. Therefore, the effects of penicillin and clindamycin treatments on reducing bacterial cytotoxicity were evaluated at MOI $=5$. Results showed that SCN162 had low cytotoxicity, and the supplementation of antibiotics after infection showed no effects on reducing SCN162-mediated cell damage (Figure 5A). Treatment of SCN157-infected cells with penicillin and penicillin plus clindamycin showed 2.25and 5-fold decrease in cell damage, respectively (Figure 5A). Furthermore, similar results were also observed in PMAactivated U937 cells infected with mixed SCN162 and SCN157 (Figure 5A).

In order to elucidate whether clindamycin could reduce the cytotoxicity caused by intracellular bacteria, SCN162- and SCN157-mediated cell damage with or without cytochalasin D was compared. Similar to the results shown in Figures 3C, $\mathbf{5 A}$, cytochalasin $\mathrm{D}$ or antibiotic treatments did not reduce SCN162-mediated cell damage (Figure 5B). Cytochalasin D and penicillin treatment reduced the SCN157-mediated cell damage 


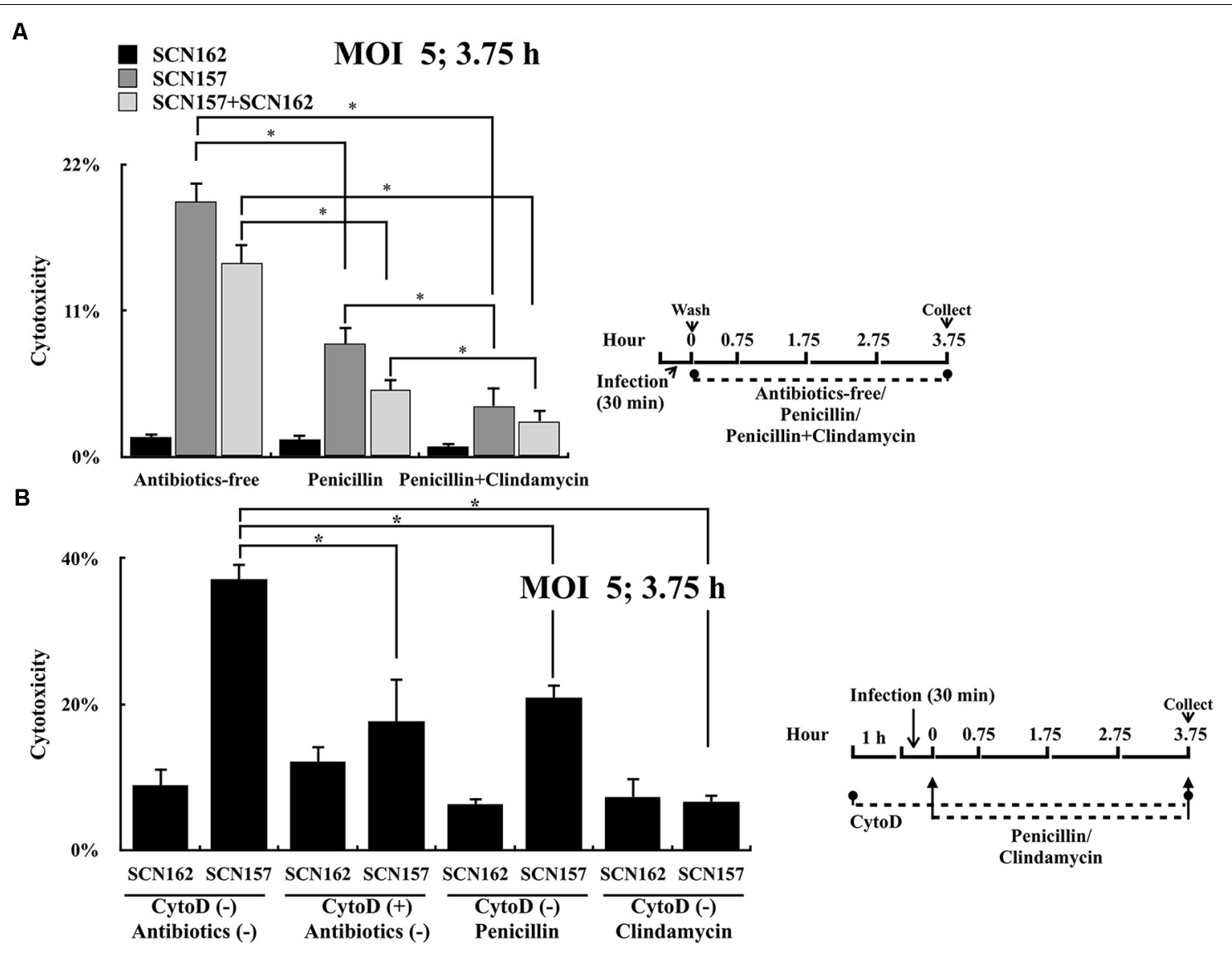

FIGURE 5 | Cytotoxicity of the capsule-deficient A20 (SCN162) and AP3 (SCN157) on PMA-activated U937 cells with or without penicillin, clindamycin, and cytochalasin D treatment after infection. (A) Cytotoxicity of SCN162 and SCN157 on PMA-activated U937 cells with or without antibiotic treatment after $3.75 \mathrm{~h}$ of infection. (B) Cytotoxicity of SCN162 and SCN157 on PMA-activated U937 cells with or without cytochalasin D or antibiotic treatments after $3.75 \mathrm{~h}$ of infection. The right panels of $\mathbf{( A , B )}$ show the infection protocols. Error bars represent the standard deviations. ${ }^{*} p<0.05$.

by approximately 2 -fold compared to the untreated conditions. Furthermore, clindamycin treatment reduced the SCN157mediated cell damage by approximately 5.5-fold compared to the untreated conditions (Figure 5B). These results support that the intracellular SCN157 plays important roles in causing cell damage. More importantly, virulence of intracellular SCN157 could be inhibited effectively by clindamycin, attenuating bacterial cytotoxicity.

\section{DISCUSSION}

Mutations in the $\operatorname{cov} R$ and $\operatorname{cov} S$ gene in GAS result in increase in bacterial virulence and are associated with severe manifestations (Sumby et al., 2006; Ikebe et al., 2010). Although the immune system has been considered an important pressure to select $\operatorname{cov} R$ and $\operatorname{cov} S$ mutants during infection (Li et al., 2014), the specific environmental niche or stress required for selecting these mutants has not been comprehensively investigated. Results from the present study showed that the intracellular animal-passage covS mutant has better survival fitness than the wild-type strain in phagocytic cells. In addition, the intracellular covS mutant has more important roles in causing cell damages than the intracellular wild-type strain and extracellular $\operatorname{cov} S$ mutant. These findings not only suggest that covS mutants can be selected in the intracellular niche of phagocytic cells, but also indicate that intracellular GAS can have important roles in invasive infections.

Mutations in the $\operatorname{cov} R$ or $\operatorname{cov} S$ gene result in the overproduction of hyaluronic acid capsule, and these mutants are highly resistant to phagocytosis (Ravins et al., 2000; Sumby et al., 2006). Nonetheless, pathogen variants rise while bacteria replicate. GAS has been shown to survive and replicate in the intracellular niche of different cell types (Medina et al., 2003b; Barnett et al., 2013; Lu et al., 2015). The hyaluronic acid capsule has no critical roles in GAS intracellular survival (Hertzen et al., 2010). Furthermore, capsule-deficient emm4- and emm89-type strains were isolated from patients with invasive GAS infections (Henningham et al., 2014; Friaes et al., 2015a; Zhu et al., 2015), suggesting that the hyaluronic acid capsule is dispensable for GAS to cause severe manifestations. Although we artificially attenuated the ability of GAS to resist phagocytosis by inactivating the capsule production, these mutants still provided critical information about how intracellular GAS interacted with phagocytic cells. 
Results from this study showed that the intracellular capsule-deficient animal-passage $\operatorname{cov} S$ mutant caused more cell damage than the intracellular capsule-deficient wild-type and extracellular animal-passage covS mutant (Figures 1C, 3C). In addition, inactivation of the SLO expression in the capsuledeficient animal-passage covS mutant reduced its cytotoxicity (Figure 3D). These findings are consistent with the previously reported model, which is the cytotoxic effect of SLO depends on phagocytic uptake of GAS (Love et al., 2012). In the present study, our competitive infection model further showed that the capsule-deficient wild-type strain was outcompeted by the capsule-deficient animal-passage $\operatorname{cov} S$ mutant in phagocytic cells (Figures $\mathbf{2 B}, \mathbf{C}$ ), and SLO is the determinant factor to provide selective advantages for intracellular GAS during infection (Figure 4). Therefore, these results not only suggest that the increased SLO production of the covs mutant is critical to enhance its survival fitness in phagocytic cells but indicating that intracellular covs mutant may contribute significantly to the increase in bacterial invasiveness during infection.

Mutations in the $\operatorname{cov} S$ gene result in the upregulation of SLO, but repress SpeB production (Sumby et al., 2006). SpeB is an important virulence factor that contributes to severe tissue damage and invasive infection (Lukomski et al., 1997; Olsen and Musser, 2010; Olsen et al., 2015). In addition, the SpeB protease was reported to help M1T1 clone of GAS escape from intracellular autophagosome killing (Barnett et al., 2013). Although $\operatorname{cov} S$ mutant is considered an invasive strain, whether the inactivation of $\mathrm{SpeB}$ in this mutant contributes directly to increased virulence and invasiveness is still under debate (Olsen et al., 2015). The emm1-type A20 strain used in this study has a high level of SpeB production (Chiang-Ni et al., 2009; Barnett et al., 2013). Our results showed that inactivation of SLO production in the capsule-deficient animal-passage covS mutant, but not inactivation of the SpeB protease activity in the capsule-deficient A20 strain, attenuated bacterial cytotoxicity on PMA-activated U937 cells (Figures 3D,E). These results suggest that the SpeB does not have critical roles in GAS survival in the intracellular niche of phagocytic cells. Furthermore, these results also provide an insight to explain why the SpeB-negative covS mutant can be selected by the immune system during infection.

GAS is one of the most important pathogens causing severe soft-tissue infections such as cellulitis and necrotizing fasciitis (Olsen and Musser, 2010). The presentations of cellulitis and necrotizing fasciitis at the early stage are similar. Nonetheless, necrotizing fasciitis is a rapidly progressive disease with severe tissue destruction and high mortality (Stevens and Bryant, 2017).

\section{REFERENCES}

Athey, T. B., Teatero, S., Sieswerda, L. E., Gubbay, J. B., Marchand-Austin, A., Li, A., et al. (2016). High incidence of invasive group A Streptococcus disease caused by strains of uncommon emm types in Thunder Bay, Ontario, Canada. J. Clin. Microbiol. 54, 83-92. doi: 10.1128/JCM.02201-15

Aziz, R. K., Ismail, S. A., Park, H. W., and Kotb, M. (2004). Post-proteomic identification of a novel phage-encoded streptodornase, Sda1, in invasive M1T1
Therefore, the early diagnosis and treatment of necrotizing fasciitis are crucial (Olsen and Musser, 2010; Stevens and Bryant, 2017). GAS strains with mutations in the $\operatorname{cov} R$ or $\operatorname{cov} S$ genes are more frequently isolated from patients with necrotizing fasciitis than from patients with mild pharyngitis (Ikebe et al., 2010; Friaes et al., 2015b). Eliminating these invasive mutants in the early stage of infection may prevent severe soft-tissue destructions. The present study showed that the treatment of infected phagocytic cells with clindamycin, but not penicillin, attenuated the virulence of intracellular capsule-deficient animalpassage $\operatorname{cov} S$ mutant (Figure 5). These results not only support that clindamycin should be used to treat patients with invasive GAS infection, but also suggest that killing or inactivating intracellular GAS could be a potential strategy to prevent severe tissue destructions of invasive GAS infection.

Although considered an extracellular pathogen, GAS is reported to survive and replicate in phagocytic cells and several other types of mammalian cells. In addition, studies have suggested that intracellular GAS has important roles in chronic infection, recurrent infection, asymptomatic infection, and failure of penicillin treatment (Osterlund et al., 1997; Sela and Barzilai, 1999; Podbielski et al., 2003; Kaplan et al., 2006; Oliver et al., 2007). The present study further suggests that intracellular invasive covS mutants can have important roles in the development of severe invasive GAS infection.

\section{AUTHOR CONTRIBUTIONS}

CC-N, C-HL, and C-HC conceived or designed the study. Y-AS acquired, analyzed, or interpreted the data. CC-N wrote the manuscript.

\section{FUNDING}

This work was supported by parts of grants from Chang Gung Memorial Hospital, LinKou, Taiwan (CMRPD1E0101-3 and BMRPD19) and Ministry of Science and Technology, Taiwan (MOST 106-2320-B-182-023-MY3).

\section{SUPPLEMENTARY MATERIAL}

The Supplementary Material for this article can be found online at: https://www.frontiersin.org/articles/10.3389/fmicb. 2018.02592/full\#supplementary-material

Streptococcus pyogenes. Mol. Microbiol. 54, 184-197. doi: 10.1111/j.1365-2958. 2004.04255.x

Barnett, T. C., Liebl, D., Seymour, L. M., Gillen, C. M., Lim, J. Y., Larock, C. N., et al. (2013). The globally disseminated M1T1 clone of group A Streptococcus evades autophagy for intracellular replication. Cell Host Microbe 14, 675-682. doi: 10.1016/j.chom.2013.11.003

Beres, S. B., Sylva, G. L., Barbian, K. D., Lei, B., Hoff, J. S., Mammarella, N. D., et al. (2002). Genome sequence of a serotype M3 strain of group A Streptococcus: 
phage-encoded toxins, the high-virulence phenotype, and clone emergence. Proc. Natl. Acad. Sci. U.S.A. 99, 10078-10083. doi: 10.1073/pnas.152298499

Chen, C. Y., Luo, S. C., Kuo, C. F., Lin, Y. S., Wu, J. J., Lin, M. T., et al. (2003). Maturation processing and characterization of streptopain. J. Biol. Chem. 278, 17336-17343. doi: 10.1074/jbc.M209038200

Chiang-Ni, C., Chu, T. P., Wu, J. J., and Chiu, C. H. (2016). Repression of Rgg but not upregulation of LacD.1 in emm1-type covS mutant mediates the SpeB repression in group A Streptococcus. Front. Microbiol. 7:1935. doi: 10.3389/ fmicb.2016.01935

Chiang-Ni, C., Tseng, H. C., Hung, C. H., and Chiu, C. H. (2017). Acidic stress enhances CovR/S-dependent gene repression through activation of the $\operatorname{cov} R / S$ promoter in emm1-type group A Streptococcus. Int. J. Med. Microbiol. 307, 329-339. doi: 10.1016/j.ijmm.2017.06.002

Chiang-Ni, C., Zheng, P. X., Ho, Y. R., Wu, H. M., Chuang, W. J., Lin, Y. S., et al. (2009). emm1/Sequence type 28 strains of group A streptococci that express $\operatorname{cov} R$ at early stationary phase are associated with increased growth and earlier SpeB secretion. J. Clin. Microbiol. 47, 3161-3169. doi: 10.1128/JCM.00202-09

Elsinghorst, E. A. (1994). Measurement of invasion by gentamicin resistance. Methods Enzymol. 236, 405-420. doi: 10.1128/JCM.00202-09

Engelthaler, D. M., Valentine, M., Bowers, J., Pistole, J., Driebe, E. M., Terriquez, J., et al. (2016). Hypervirulent emm59 clone in invasive group A Streptococcus outbreak, Southwestern United States. Emerg. Infect. Dis. 22, 734-738. doi: 10.3201/eid2204.151582

Friaes, A., Machado, M. P., Pato, C., Carrico, J., Melo-Cristino, J., and Ramirez, M. (2015a). Emergence of the same successful clade among distinct populations of emm89 Streptococcus pyogenes in multiple geographic regions. mBio 6:e0183815. doi: $10.1128 / \mathrm{mBio} .01780-15$

Friaes, A., Pato, C., Melo-Cristino, J., and Ramirez, M. (2015b). Consequences of the variability of the CovRS and RopB regulators among Streptococcus pyogenes causing human infections. Sci. Rep. 5:12057. doi: 10.1038/srep12057

Garcia, A., Serrano, A., Abril, E., Jimenez, P., Real, L. M., Canton, J., et al. (1999). Differential effect on U937 cell differentiation by targeting transcriptional factors implicated in tissue- or stage-specific induced integrin expression. Exp. Hematol. 27, 353-364. doi: 10.1038/srep12057

Goldmann, O., Rohde, M., Chhatwal, G. S., and Medina, E. (2004). Role of macrophages in host resistance to group A streptococci. Infect. Immun. 72, 2956-2963. doi: 10.1128/iai.72.5.2956-2963.2004

Hancz, D., Westerlund, E., Bastiat-Sempe, B., Sharma, O., Valfridsson, C., Meyer, L., et al. (2017). Inhibition of inflammasome-dependent interleukin $1 B$ production by streptococcal $\mathrm{NAD}^{+}$-glycohydrolase: evidence for extracellular activity. mBio 8:e00756-17. doi: 10.1128/mBio.00756-17

Henningham, A., Yamaguchi, M., Aziz, R. K., Kuipers, K., Buffalo, C. Z., Dahesh, S., et al. (2014). Mutual exclusivity of hyaluronan and hyaluronidase in invasive group A Streptococcus. J. Biol. Chem. 289, 32303-32315. doi: 10.1074/jbc.M114. 602847

Hertzen, E., Johansson, L., Wallin, R., Schmidt, H., Kroll, M., Rehn, A. P., et al. (2010). M1 protein-dependent intracellular trafficking promotes persistence and replication of Streptococcus pyogenes in macrophages. J. Innate Immun. 2, 534-545. doi: 10.1159/000317635

Hughes, G. J., Van Hoek, A. J., Sriskandan, S., and Lamagni, T. L. (2015). The cost of hospital care for management of invasive group A streptococcal infections in England. Epidemiol. Infect. 143, 1719-1730. doi: 10.1017/S0950268814002489

Ikebe, T., Ato, M., Matsumura, T., Hasegawa, H., Sata, T., Kobayashi, K., et al. (2010). Highly frequent mutations in negative regulators of multiple virulence genes in group A streptococcal toxic shock syndrome isolates. PLoS Pathog. 6:e1000832. doi: 10.1371/journal.ppat.1000832

Kaplan, E. L., Chhatwal, G. S., and Rohde, M. (2006). Reduced ability of penicillin to eradicate ingested group A streptococci from epithelial cells: clinical and pathogenetic implications. Clin. Infect. Dis. 43, 1398-1406. doi: 10.1086/508773

Kim, J. H., and Cheong, H. K. (2018). Increasing number of scarlet fever cases, South Korea, 2011-2016. Emerg. Infect. Dis. 24, 172-173. doi: 10.3201/eid2401. 171027

Lawrence, T., and Natoli, G. (2011). Transcriptional regulation of macrophage polarization: enabling diversity with identity. Nat. Rev. Immunol. 11, 750-761. doi: $10.1038 / \mathrm{nri} 3088$

Lee, C. F., Cowling, B. J., and Lau, E. H. Y. (2017). Epidemiology of reemerging scarlet fever, Hong Kong, 2005-2015. Emerg. Infect. Dis. 23, 1707-1710. doi: $10.3201 /$ eid2310.161456
Li, J., Liu, G., Feng, W., Zhou, Y., Liu, M., Wiley, J. A., et al. (2014). Neutrophils select hypervirulent CovRS mutants of M1T1 group A Streptococcus during subcutaneous infection of mice. Infect. Immun. 82, 1579-1590. doi: 10.1128/ IAI.01458-13

Love, J. F., Tran-Winkler, H. J., and Wessels, M. R. (2012). Vitamin D and the human antimicrobial peptide LL-37 enhance group A Streptococcus resistance to killing by human cells. mBio 3:e00394-12. doi: 10.1128/mBio.0039412

Lu, S. L., Kuo, C. F., Chen, H. W., Yang, Y. S., Liu, C. C., Anderson, R., et al. (2015). Insufficient acidification of autophagosomes facilitates group A Streptococcus survival and growth in endothelial cells. mBio 6:e01435-15. doi: 10.1128/mBio. 01435- 15

Lukomski, S., Sreevatsan, S., Amberg, C., Reichardt, W., Woischnik, M., Podbielski, A., et al. (1997). Inactivation of Streptococcus pyogenes extracellular cysteine protease significantly decreases mouse lethality of serotype M3 and M49 strains. J. Clin. Invest. 99, 2574-2580. doi: 10.1172/JCI119445

Medina, E., Goldmann, O., Toppel, A. W., and Chhatwal, G. S. (2003a). Survival of Streptococcus pyogenes within host phagocytic cells: a pathogenic mechanism for persistence and systemic invasion. J. Infect. Dis. 187, 597-603. doi: 10.1086/ 373998

Medina, E., Rohde, M., and Chhatwal, G. S. (2003b). Intracellular survival of Streptococcus pyogenes in polymorphonuclear cells results in increased bacterial virulence. Infect. Immun. 71, 5376-5380. doi: 10.1128/iai.71.9.5376-5380.2003

Oliver, M. A., Garcia-Rey, C., Bosch, R., and Alberti, S. (2007). Evaluation of the ability of erythromycin-resistant and -susceptible pharyngeal group A Streptococcus isolates from Spain to enter and persist in human keratinocytes. J. Med. Microbiol. 56(Pt 11), 1485-1489. doi: 10.1099/jmm.0.47 203-0

Olsen, R. J., and Musser, J. M. (2010). Molecular pathogenesis of necrotizing fasciitis. Annu. Rev. Pathol. 5, 1-31. doi: 10.1146/annurev-pathol-121808102135

Olsen, R. J., Raghuram, A., Cantu, C., Hartman, M. H., Jimenez, F. E., Lee, S., et al. (2015). The majority of 9,729 group A Streptococcus strains causing disease secrete SpeB cysteine protease: pathogenesis implications. Infect. Immun. 83, 4750-4758. doi: 10.1128/IAI.00989-15

O’Neill, A. M., Thurston, T. L., and Holden, D. W. (2016). Cytosolic replication of group A Streptococcus in human macrophages. mBio 7:e00020-16. doi: 10.1128/ mBio.00020-16

O'Seaghdha, M., and Wessels, M. R. (2013). Streptolysin O and its co-toxin NADglycohydrolase protect group A Streptococcus from xenophagic killing. PLoS Pathog. 9:e1003394. doi: 10.1371/journal.ppat.1003394

Osterlund, A., Popa, R., Nikkila, T., Scheynius, A., and Engstrand, L. (1997). Intracellular reservoir of Streptococcus pyogenes in vivo: a possible explanation for recurrent pharyngotonsillitis. Laryngoscope 107, 640-647. doi: 10.1097/ 00005537-199705000-00016

Podbielski, A., Beckert, S., Schattke, R., Leithauser, F., Lestin, F., Gossler, B., et al. (2003). Epidemiology and virulence gene expression of intracellular group A streptococci in tonsils of recurrently infected adults. Int. J. Med. Microbiol. 293, 179-190. doi: 10.1078/1438-4221-00253

Ravins, M., Jaffe, J., Hanski, E., Shetzigovski, I., Natanson-Yaron, S., and Moses, A. E. (2000). Characterization of a mouse-passaged, highly encapsulated variant of group A Streptococcus in in vitro and in vivo studies. J. Infect. Dis. 182, 1702-1711. doi: 10.1086/317635

Renard, C., Vanderhaeghe, H. J., Claes, P. J., Zenebergh, A., and Tulkens, P. M. (1987). Influence of conversion of penicillin $G$ into a basic derivative on its accumulation and subcellular localization in cultured macrophages. Antimicrob. Agents Chemother. 31, 410-416. doi: 10.1128/AAC.31.3.410

Sela, S., and Barzilai, A. (1999). Why do we fail with penicillin in the treatment of group A Streptococcus infections? Ann. Med. 31, 303-307. doi: 10.3109/ 07853899908995895

Staali, L., Bauer, S., Morgelin, M., Bjorck, L., and Tapper, H. (2006). Streptococcus pyogenes bacteria modulate membrane traffic in human neutrophils and selectively inhibit azurophilic granule fusion with phagosomes. Cell. Microbiol. 8, 690-703. doi: 10.1111/j.1462-5822.2005.00662.x

Stevens, D. L., Bisno, A. L., Chambers, H. F., Dellinger, E. P., Goldstein, E. J., Gorbach, S. L., et al. (2014). Practice guidelines for the diagnosis and management of skin and soft tissue infections: 2014 update by the Infectious Diseases Society of America. Clin. Infect. Dis. 59, e10-e52. doi: 10.1093/cid/ ciu 444 
Stevens, D. L., and Bryant, A. E. (2017). Necrotizing soft-tissue infections. N. Engl. J. Med. 377, 2253-2265. doi: 10.1056/NEJMra160 0673

Stollerman, G. H., and Dale, J. B. (2008). The importance of the group A Streptococcus capsule in the pathogenesis of human infections: a historical perspective. Clin. Infect. Dis. 46, 1038-1045. doi: 10.1086/52 9194

Sumby, P., Porcella, S. F., Madrigal, A. G., Barbian, K. D., Virtaneva, K., Ricklefs, S. M., et al. (2005). Evolutionary origin and emergence of a highly successful clone of serotype M1 group A Streptococcus involved multiple horizontal gene transfer events. J. Infect. Dis. 192, 771-782. doi: 10.1086/43 2514

Sumby, P., Whitney, A. R., Graviss, E. A., DeLeo, F. R., and Musser, J. M. (2006). Genome-wide analysis of group A streptococci reveals a mutation that modulates global phenotype and disease specificity. PLoS Pathog. 2:e5. doi: 10.1371/journal.ppat.0020005

Walker, M. J., Hollands, A., Sanderson-Smith, M. L., Cole, J. N., Kirk, J. K., Henningham, A., et al. (2007). DNase Sdal provides selection pressure for a switch to invasive group A streptococcal infection. Nat. Med. 13, 981-985. doi: $10.1038 / \mathrm{nm} 1612$

Zhu, L., Olsen, R. J., Nasser, W., and Musser, J. M. (2015). Trading capsule for increased cytotoxin production: contribution to virulence of a newly emerged clade of emm89 Streptococcus pyogenes. mBio 6:e01378-15. doi: 10.1128/mBio. 01378-15

Conflict of Interest Statement: The authors declare that the research was conducted in the absence of any commercial or financial relationships that could be construed as a potential conflict of interest.

Copyright (c) 2018 Chiang-Ni, Shi, Lai and Chiu. This is an open-access article distributed under the terms of the Creative Commons Attribution License (CC BY). The use, distribution or reproduction in other forums is permitted, provided the original author(s) and the copyright owner(s) are credited and that the original publication in this journal is cited, in accordance with accepted academic practice. No use, distribution or reproduction is permitted which does not comply with these terms. 